\title{
A música em sua contemporaneidade digital: os desafios da construção de uma memória ${ }^{\mathrm{I}}$
}

Gabriel de Oliveira Piotto

\section{Resumo}

Com a rápida evolução digital apresentada nos últimos doze anos, a maneira de arquivar, escutar, produzir e compartilhar música foi substancialmente alterada. Diversos fatores passaram, porém, a interferir substancialmente na dinâmica interna de funcionamento e lógica do próprio meio digital. Analisar como se dão essas novas práticas mostra-se como um exercício de compreender como esse novo meio engendra e preserva a memória musical, suscitando, também, necessidades de uma nova postura metodológica e discursiva frente a essas novas problemáticas.

Palavras-chave: Música - Memória - Acervos Digitais - Arquivos Digitais Construção da Memória Musical.

I Este relatório apresenta resultados obtidos a partir das pesquisas de iniciação científica, processo nº 20I2/22336-8, Fundação de Amparo à Pesquisa do Estado de São Paulo (Fapesp). 


\section{Introdução}

O estudo dos meios em que hoje a música está inserida apresenta inconstâncias indispensáveis para o entendimento daqueles e o estudo desta. Mais que um novo dinamismo nas formas de movimentação e duração, a efemeridade ágil desses meios em questão constitui, na verdade, a natureza de uma subestrutura de constância em sua inconstância. A força que reside na nova dinâmica digital provém da própria desestabilização que esta passa a aplicar dentro das antigas relações pessoais, de comunicação, difusão, controle e poder. É a ampliação das possibilidades que surgem concomitantes ao desenvolvimento digital e social na internet que aparecem enquanto transformadoras para além de sua esfera. $\mathrm{O}$ avanço do acesso à internet de maneira instantânea - geográfica e temporalmente -, com a evolução dos smartphones e a internet sem fio, parece diluir o limite, agora tênue, entre o mundo digital e o mundo real. Dentro, portanto, da relação entre esses dois, o poder que o meio digital tem apresentado enquanto transformador se mostra demasiadamente concreto nas sociedades atuais. Desde facilitar a comunicação, realizar algumas tarefas cotidianas, entrar em contato com algumas pessoas distantes - outras próximas -, até organizar mobilizações e protestos políticos para a derrubada de ditadores e mudanças no cenário político vigente ${ }^{2}$, a impressão suscitada é de uma transformação ampla em diversos setores dentro e fora da web. O momento de crise da democracia formal, assim como afirmam alguns estudiosos do assunto, com inúmeros protestos eclodindo por diversos países desde a Primavera Árabe, mostra novas formas de organização dos questionamentos que passam justamente por essas novas ferramentas. A existência e o desenvolvimento das redes sociais digitais oferecem às sociedades justamente a capacidade de exercer papéis políticos de maneira inédita (CASTELLS, 20IO). A possibilidade não só de desmentir, mas também produzir e compartilhar informações questiona o status quo da

\footnotetext{
2 Um relatório da Dubai School of Government atribui a propagação do movimento conhecido como Primavera Árabe, que teve início no ano de 20II, às redes sociais como o Twitter e o Facebook. Na Tunísia, ponto inicial da série de revoltas, foi constatado o rápido aumento no número de usuários cadastrados no Facebook. Entre novembro de 2010 e janeiro de $201 \mathrm{I}$, duzentas mil pessoas criaram uma conta na página. Foi nesse mesmo momento que os tunisianos foram às ruas para exigir a queda do presidente, há 23 anos no poder, Zine el Abidine Ben Ali. No dia I4 de janeiro, por exemplo, Ben Ali renunciou e fugiu para a Arábia Saudita, gerando o maior pico de acessos no Twitter por tunisianos. Para mais informações sobre o poder das redes sociais dentro na Primavera Árabe acessar: http://mundorama. net/2012/II/O6/o-papel-das-redes-sociais-na-primavera-arabe-de-20II-implicacoes-para-a-ordem-internacional-por-viviane-brunelly-araujo-tavares/.
} 
dominação da comunicação por alguns agentes, colocando em xeque justamente o poder destes através do controle das informações.

É esta dinâmica produtora e reprodutora responsável, portanto, pela aproximação do caráter ativo e passivo dentro desta lógica. É a ampliação do papel ativo nas diversas ações da sociedade através da rede digital que configura um novo horizonte de possibilidades e uma nova dinâmica entre os novos e antigos agentes. Os monitores dos computadores atuais banham as faces dos internautas com aquilo que seria a possibilidade das novas - e mais verossímeis - luzes. Não as luzes do sprit do século XVIII, mas, sim, possibilidades reais de desenvolvimentos e transformações substanciosas. A capacidade de uma ampla digitalização e compartilhamento de documentos, como pretendem algumas bibliotecas digitais ${ }^{3}$, ou até mesmo a simplicidade em se criar uma página para compartilhamento ou produção de conteúdos parecem mostrar um dos caminhos positivos do uso das ferramentas tecnológicas disponíveis. Tais facilidades, dentro das novas possibilidades, acabam, porém, por esbarrar em questões complexas de controle com anseios mercadológicos e lucrativos. Ou seja, a possibilidade de uma real biblioteca universal ou de incontáveis páginas na internet que compartilhem música sem saírem do espectro legal depende, hoje, dos embates entre forças diversas que imergem ou se aproximam deste meio digital.

Não se trata, porém, de alguma exclusividade. Assim como apontou Juan Andrés Bresciano, a aparição de um novo modo de expressão (como o surgimento da escrita, por exemplo) gerou profundas mudanças, assim como o meio de armazenamento desta expressão (a substituição do pergaminho pelo papel como um suporte para a escrita) (BRESGIANO, 20IO, p. IO). A força tecnológica digital está, porém, na combinação de diversas expressões fundamentais (escrita, imagens, conteúdos audiovisuais) concomitante com a crescente autonomia individual de produção e compartilhamento do conteúdo em si. O bombardeio das informações contemporâneas tem sido, mais do que acompanhado, produto do próprio meio digital responsável pela imediata produção de informações rápidas e dinâmicas dia após dia. É o constante sentimento de perda de conteúdos em meio à torrente de novos conteúdos postados que configura, também, a relação substanciosa da reestruturação e da ressignificação da memória e do esquecimento.

A internet - e todo o seu meio -, porém, não é uma ferramenta finalizada e seus usos e desusos estão à mercê do que se engendra nela. O compar-

3 Acerca das bibliotecas digitais acessar: http://www.diplomatique.org.br/edicoes_especiais_artigo. php?id=2. 
tilhamento de informações e conteúdos na internet hoje se apresenta como um dos principais debates dentro da esfera digital e dos novos tratos que esta exige. Alguns dos principais campos em que este embate tem se dado são o jurídico e o legislativo. Assim como o processo natural das leis, o acompanhamento concomitante destas com a evolução tecnológica de seu tempo se dá de forma orgânica e sensata. Ideias sólidas se desintegram em outras. Isso, porém, assim decorre quando não existe, do lado contrário à mudança, grandes interesses mercadológicos, institucionais ou governamentais (LESSIG, 2006, p. 25). Por isso, o cenário da internet atual é de grandes gravadoras, empresas e organizações governamentais que lutam contra as modificações que o meio digital pode trazer para a cultura e seu mercado. Como grandes objetos sólidos, tentam conter os líquidos digitais que buscam ocupar o espaço vazio que encontram. Os embates, portanto, entre as velhas e as novas formas são também embates entre sólidos e líquidos, memória e esquecimento, em que cada um de seus desdobramentos é responsável por cada nova construção de uma ferramenta com potenciais diversos e distintos.

As formas de arte, ao mesmo tempo, registram em seu âmago criativo o contexto onde estão inseridas, assim como a própria história da humanidade. Em seus processos criativos, o contexto surge e ressurge através de diversas formas de expressão. Sendo internos e concomitantes à sua composição, são os fatores externos das técnicas, formas, interesses e convicções aqueles que colorem e passam a influenciar cada obra. Mas são também os fatores após sua composição que fazem da obra de arte sua ligação com o contexto. Sejam os mais subjetivos caminhos do gosto, ou os concretos fatores ligados ao documento e sua preservação, a obra de arte não tem seu fim em si mesmo, uno e imutável. É o processo de transmutação, ao longo do tempo que uma obra percorre, o primeiro ponto em que o meio passa a interferir nesta.

Assim como passam a sofrer a eterna recontextualização, as obras de arte estão sempre subordinadas aos meios técnicos de seus tempos. Como uma arte no tempo, a música desaparece assim que é executada, restando a ela que o primeiro registro se dê na memória, depois na linguagem e notação. O século XX trouxe em sua modernidade a "música em conserva" materializada nos fonogramas e, com isso, toda uma transformação dos processos de memorização, registro, divulgação e reprodução da música. Criou-se um novo horizonte de técnicas, sons, sociabilidades e escutas (MORAES, 2OIO, p. II). Assim como as diversas transformações e mudanças que os fonogramas trouxeram, o neófito universo digital mudou substancialmente os documentos musicais - no que tange à grandeza material e não material - e, consequentemente, suas práticas em torno destes (registro, procura, escuta, sociabilidade, 
entre outros). A construção da memória musical engendrada atualmente nos meios digitais, portanto, apresenta novas características e formas de comportamento, fundamentais de serem entendidas e apreendidas tendo como preocupação justamente entender essa nova memória que se forma e suas novas e antigas características.

\section{Da conserva ao digital: as novas particularidades da memória}

Segundo José Geraldo e Cacá Machado em "Música em conserva", a formação de acervos e arquivos ao longo dos séculos XIX e XX mudou significativamente. Passando do arquivamento, ainda precário, do século XIX para os colecionistas do século XX, temos uma mudança significativa, principalmente no ato de arquivar música. O surgimento dos fonogramas possibilitaram essas mudanças. $\mathrm{O}$ início das coleções feitas por amantes da música marcou o começo do abandono dos discursos organizados e das bases institucionais. A formação de uma cultura musical se deu com um "conjunto composto por uma cultura oral, urbanizada, marcada pelo divertimento e definitivamente pelos meios de comunicação que tornaram os caminhos de constituição de sua memória e de sua história bem mais tortuosos e fragmentados" (MORAIS \& MACHADO, 2OII, p. I73).

Essa nova dinâmica se aproximou do que Michel de Certeau classificou como exercício de guerrilha, algo oposto aos discursos estratégicos (como, por exemplo, o movimento folclorista do século XIX). O que temos é a diferença básica entre os "espaços" de "atuação". Enquanto os discursos estratégicos criavam e ocupavam os "espaços" institucionais, a guerrilha acabava por estar presente em diversos "lugares" (GERTEAU, I994) de memória (ruas, teatros, festas, clubes, cafés e bares e, posteriormente, na indústria fonográfica e radiofônica). Os registros, passando a ter origens nas várias culturas e práticas da sociedade brasileira, acabaram sedimentando-se nas memórias pessoais do outro, comunitárias, urbanas, nas relações mestre-aprendiz e nos meios de comunicação (MORAIS \& MACHADO, 20II, p. I73 e I74).

Outro aspecto importante está na participação do Estado. Durante o século XX, por exemplo, a aproximação do Estado com os acervos de música deu-se depois do início de práticas colecionistas. Mario de Andrade, colecionador meticuloso, teve seu acervo incorporado ao Instituto de Estudos Brasileiros da Universidade de São Paulo em I968. O acervo do musicólogo alemão Curt Lange (I903-I997) que reuniu durante décadas, de maneira individual, 
um imenso material bibliográfico e de fontes primárias foi integrado à Universidade Federal de Minas Gerais ${ }^{4}$. Diversos casos semelhantes repetiram-se, como o acervo de Abrahão de Carvalho incorporado à Biblioteca Nacional.

Com a virada para o século XXI e o início das práticas privadas de construção de acervos, a dinâmica parece ter se alterado mais uma vez. O cenário digital apresenta suas diversas singularidades, ao mesmo tempo em que preserva relações e tratos anteriores dentro do processo digital. A esfera institucional e as guerrilhas têm métodos de abordagem diferentes, estratégias diversificadas e finalidades diversas, pautando-se, porém, sempre em torno de uma ideia de acervos universais a partir do momento em que estes passam a integrar a imensidão da web.

A primeira geração de computadores, como o Mac e o Windows, surgiu como uma ferramenta. Nas atividades básicas, representavam essencialmente uma extensão da máquina de escrever com suas formas glorificadas. É desse ponto que a ascensão da internet se torna algo importante e que transforma os pressupostos básicos em relação ao computador. A conexão em uma rede transforma o que era antes uma simples ferramenta com certas facilidades em um novo ambiente rico em possibilidades diversas. $O$ fato de cada vez mais pessoas estarem interligadas por uma rede na qual dados são despejados em uma grande torrente - assim como ao clicar em um link faz-se abrir uma nova janela com novas informações e outras muitas possibilidades de ampliar o acesso a outras paisagens -, cria-se um mundo no qual podemos nos projetar e explorá-lo. É praticamente impossível imaginar a quantidade de informações que estão ao alcance de nossos dedos (JOHNSON, 200I, p. I9, 20 e 23). E é nesse ambiente heterogêneo e a priori caótico que se encontram diversificadas estratégias de legitimação, inúmeros critérios de avaliação e seleção, diversas maneiras de se trabalhar com o material e com o público-alvo, entre outras singularidades. As práticas de guerrilha e os discursos oficiais parecem, porém, conservar algumas características apontadas por Certeau. A imensidão de blogs e páginas passa a tentar preencher o vazio com velhas práticas em novas ferramentas. Iniciativas independentes que cresceram tentando abrigar tendências e artistas excluídos pela lógica formal estética de mercado encontraram um novo horizonte de possibilidades em suas atividades. Antes trocando, distribuindo ou vendendo fitas $\mathrm{K} 7$ e, depois, CDs, os espaços independentes de compartilhamento de música migraram para as ferramentas digitais do download e do stream.

4 Acervo Curt Lange: www.curtlange.bu.ufmg.br/. 


\section{II.I. Fluidos digitais: o caráter líquido da nova dinâmica}

Uma nova dinâmica dos comportamentos orgânicos dos acervos digitais de música, e seus fluxos de informações, nos apresenta um arranjo de circunstâncias e disposições em um cenário não plano, mas profundo e largo, que permite uma observação de diversos ângulos, ao mesmo tempo em que observações no mesmo ponto, mas em tempos diferentes, nos apresentam também a possibilidade de mudanças no resultado observado. A inconstância, mobilidade e, principalmente, fluidez dos fluxos de informação observados nos acervos de música - e dos próprios agentes que constroem esse cenário - nos apresentam grande aproximação com a condição dos líquidos e suas características. A fluidez pode ser colocada como qualidade dos líquidos e dos gases (sendo isso o que os distingue dos sólidos). Não suportam forças tangenciais ou deformantes quando se encontram imóveis, sofrendo, assim, constantes mudanças de forma quando são submetidos a tal tensão (BAUMAN, 2008, p. 7).

O que essas características dos fluidos nos apresentam é que os líquidos - diferente dos sólidos - não mantêm sua forma com facilidade e nem fixam espaço. Em contrapartida, os sólidos têm dimensões espaciais definidamente claras, "mas neutralizam o impacto e, portanto, diminuem a significação do tempo (resistem efetivamente a seu fluxo ou o tornam irrelevante)" (Idem, 2008 , p. 7). Já os fluidos contam muito mais com a ação do tempo, estando constantemente propensos a mudar de forma. "Ao descrever os sólidos, podemos ignorar inteiramente o tempo; ao descrever os fluidos, deixar o tempo de fora seria um grave erro. Descrições de líquidos são fotos instantâneas, que precisam ser datadas" (Idem, 2008, p. 7).

A sensação e, muitas vezes, a caracterização do meio digital como algo leve e dinâmico advêm de características aproximáveis às dos fluidos, esses que se movem facilmente, transbordam, vazam, inundam, pingam, são filtrados, destilados, respigam; e, principalmente, não são facilmente contidos ${ }^{5}$. Há líquidos, porém, que centímetro cúbico por centímetro cúbico são mais pesados que muitos sólidos, mas ainda assim tendemos a associá-los como mais leves. 'Associamos 'leveza' ou 'ausência de peso' à mobilidade e à inconstância:

5 Zygmunt Bauman cita que "descrições de líquidos são fotos instantâneas, que precisam ser datadas", assim como o cenário aqui estudado. As fontes para este trabalho apresentam características de grande inconstância como, por exemplo, a alteração observada entre o primeiro levantamento de acervos e o segundo (com alguns meses de diferença), em que acervos como o http://toplinkmusical.blogspot.com. $\mathrm{br} /$ foram apagados nesse tempo; e o http://mpb4cavaleirosdampb.blogspot.com.br/, que parece ter mudado de administrador e de conteúdo para algo totalmente diferente. 
sabemos que quanto mais leve viajamos, com maior facilidade e rapidez nos movemos" (BAUMAN, 2008, p. 7). As figuras de linguagem, ou até mesmo metáforas, que tentam se aproximar da experiência de acessar os diversos caminhos que a internet oferece através dos links e hyperlinks, porém, ainda não deram conta de perpassar por todas as suas experiências e possibilidades. As ideias de rede ou galáxia não correspondem ao dinamismo digital, ao mesmo tempo em que as metáforas do surfe e da navegação não dão conta da complexidade das experiências. A falha dessas últimas está justamente na sensação de limitação do controle, em que surfar se limita à onda e navegar se limita a movimentos horizontais, deixando de lado uma sensação de movimentação em três dimensões. Através deste caminho, o ato de acessar a internet e seus meandros é como o ato de mergulho em águas profundas. Um mergulhador explorador que, com seu cilindro de oxigênio, tem tempo e capacidade de explorar por horas desde a superfície até às águas mais profundas e obscuras encontrando nestas suas fontes.

Os diversos blogs, sites e acervos digitais de música que surgem, somem e se relacionam entre eles apresentam um cenário com agentes de fluxos de informações que obedecem a uma lógica não completa de caos e aleatoriedade. Assim como cardumes, existem diversas formas de relacionamento entre estes acervos. Portanto, uma vez que cada acervo tem uma aproximação metafórica com os peixes que nadam desde a superfície até as profundezas, algumas relações entre estes agentes apresentam diversas formas de organização e relacionamento. São como grupos que passam, ou não, a deter uma lógica interna, ocupam o espaço digital e neste acabam funcionando internamente em suas individualidades e particularidades, ao mesmo tempo em que agem dentro de uma lógica maior e mais complexa. Não obstante, acervos isolados, além de se comunicarem com e adentrarem, simultaneamente, diversos cardumes diferentes, podem simplesmente manter distância dos outros agentes. Ou seja, a comunicação entre blogs sobre música popular brasileira, por exemplo, forma algo metaforicamente próximo a um cardume, mas este pode ser frequentado por blogs de música que não têm necessariamente este foco definido e restrito.

Em razão, também, da distribuição espacial, as pesquisas na internet apresentam seus resultados na forma de listas. Espacialmente verticais, portanto, alguns acervos aparecem ao longo das páginas de resultados antes que outros. Atualmente, este processo se dá através de diversas variantes. A principal delas é o valor monetário despendido em cada página ou blog. Serviços atuais garantem que, ao pagar um valor estipulado para as empresas que hospedam ou fazem pesquisas na internet, sua página aparece entre 
os primeiros resultados de busca. Outras variantes, como a quantidade de fluxos de informação trocadas entre postagens e visitantes, atuam nesta questão. Não obstante, porém, esses acervos que se encontram mais a superfície têm grande importância para a formação daqueles menores ou mais profundos ${ }^{6}$. Os cardumes, portanto, se organizam também de maneira vertical em que o mergulhador, para encontrar acervos menores e mais diversos, precisa seguir os peixes em sentido vertical, chegando até as águas mais escuras. Se o mergulhador, por fim, explorar até o limite da profundidade, encontrará aqueles que caíram em desuso ou simplesmente foram abandonados. Esses seriam os acervos esquecidos pelos donos - ou visitantes - e que lá caíram, diferente dos acervos excluídos definitivamente ${ }^{7}$.

\section{II.II. Imersão em correntes digitais}

O mergulhador cai sobre as águas e rapidamente escolhe o cardume para ser encontrado. Para isso pode-se usar uma ferramenta de busca como o Google e procurar por blog de música brasileira, por exemplo. Rapidamente, os links da superfície aparecem e um dos principais blogs do gênero surge à vista. $O$ "Um que tenha" é o segundo link na ordem, e é escolhido para iniciar a análise. Para focar no ato da exploração, abstraímos da análise o conteúdo do acervo, tendo apenas a priori ser este voltado para a música brasileira, focando nos outros acervos relacionados à questão.

A lista de links que levam a outras páginas representa essa interação de proximidade visual entre estas. Ou seja, os acervos que parecem estar próximos e são visíveis quando se encontra, primeiramente, o acervo do "Um que tenha". Logo de início, são vinte e oito relacionados. Para ter breve noção da grande variedade de caminhos possíveis a se tomar, ao escolher o acervo "Bossa brasileira" ${ }^{8}$, este contém mais vinte e quatro relacionados - podendo ter acervos iguais aos relacionados do UQT ou até mesmo este próprio. Por outro

6 Um caso que demonstra essa influência de grandes acervos em acervos menores é o do http://apiluladosom.blogspot.com.br/. Em entrevista, seu criador citou que reconhecia a importância e até colaborava com o "Um que tenha", página de compartilhamento de música com grandes resultados de compartilhamento e visitas.

7 Exemplos desses acervos são: http://umquenaotenha.wordpress.com/; http://www.baudelongplaying. com/; http://br-instrumental.blogspot.com.br/; http://musicadaminhagente.blogspot.com.br/; entre outros.

8 http://bossa-brasileira.blogspot.com.br/ 
lado, se escolher seguir pelo caminho do "Mistura brasileira" 9 , encontrar-se-ão vinte e um links para acervos de música digital. É a repetição de links relacionados entre os diversos acervos que permite a sensação descrita de movimentação em diversas dimensões: analisar um, voltar - encontrando novamente um acervo anterior ou usando a ferramenta do navegador que volta às páginas do histórico anterior - e perpassar todos os níveis de uma hierarquia entre os diversos agentes deste cenário.

A questão, porém, da importância e do tamanho de cada acervo diz respeito a uma procura horizontal de disposição de links que levará cada vez mais à profundidade. Os links estão apresentados em listas, mas essas estão assim dispostas, muitas vezes, por limitações das ferramentas à disposição dos criadores dos blogs e dos sites. Encontrar os blogs mais profundos requer muitas vezes encontrar um link destes que está ao lado - ou em cima, ou embaixo - do link de um acervo que se encontra na superfície. Por esse fato, não basta ir seguindo os diversos caminhos e a cada novo acervo visitado se tem uma gradativa imersão. Cabe ao explorador percorrer diversos meandros diferentes com a possibilidade de encontrar um acervo com pouca visibilidade logo após entrar em um com grande visibilidade - e vice-versa. É-nos apresentada, portanto, uma grande diversidade de fontes, essas que chegam a nós dispostas de maneira embaralhada e confusa.

Como suscitado acima, peixes que não pertencem a nenhum cardume são aqueles que não se fecham em um gênero específico. Seriam esses acervos em que se encontram documentos musicais dos mais diversos gêneros e países, como é o caso do "Chicken songs" Io "Feijão tropeiro" "II e outros relacionados ao "Um que tenha".

Assim poderia ser descrito um caminho a se percorrer e explorar a complexidade digital, se esta não fosse liquidamente instável. Em um período de alguns meses deste esforço de compreender as relações dos acervos digitais descritos acima, aquele que pareceu se mostrar o principal eixo de organização e irradiação de conteúdo dentro dos outros acervos relacionados a este caiu. A página do "Um que tenha", citado e tido como referência por outros agentes do cenário, teve todo o seu acervo apagado pela segunda vez. Assim como na primeira, o motivo retorna ao embate entre os interesses citados no início do texto.

9 http://amisturabrasileira.blogspot.com.br/

IO http://chickensongs.blogspot.com.br/

II http://feijaotropeiro.blogspot.com.br/ 
A indústria da música se encontra em uma fase de transição desde que o compartilhamento de música passou a ser feito também - e cada vez mais - pelo meio digital. Talvez nenhum aspecto da indústria da música tenha se alterado tanto nos últimos anos quanto a forma de distribuição aos consumidores ${ }^{12}$. Essa nova lógica de produção e consumo musical se mostra, na ordem do dia, responsável por uma grande mudança no trato e na cultura de se relacionar com a música. Grande parte das gravações mais recentes estão sob grande risco de se perderem por causa das mudanças de distribuição da indústria musical. As cópias físicas das novas, e também antigas, publicações estão sendo substituídas pelo áudio digital e distribuídas por companhias terceiras (iTunes, Amazon, eMusic). Ao mesmo tempo, a relação de compra tem se alterado e se limitado apenas ao nível pessoal, não comercial e de entretenimento que, muitas vezes, não é classificado nem como uma compra. Desse modo, sob os termos de licença, o conteúdo continua sendo uma propriedade do provedor e todos os usos ficam sob os termos de licença ${ }^{13}$.

Essa nova dinâmica traz a importante reflexão sobre como se dá, na prática, a construção de uma memória musical no meio digital. Em uma situação hipotética, aquele que teoricamente compra uma música digital não se torna o proprietário desta e está impossibilitado até mesmo de transferi-la para um herdeiro ou instituição (prática comum entre colecionadores). Ao mesmo tempo, estas licenças impossibilitam bibliotecas e acervos de comprarem áudios digitais. Quando o cenário em construção aponta para tais desfechos nos quais, por exemplo, não importa o quão importante ou em risco de preservação o arquivo esteja o colecionador não poderá doá-lo, a necessidade de construção de uma memória digital consistente se mostra de grande importância, tendo de somar preocupações que permeiam diversas esferas de um processo complexo. As tecnologias vão continuar a evoluir mais rápido do que as leis e estas, muitas vezes, acabam acompanhando tal evolução. Mas quando se trata do meio digital, temos uma realidade de mudanças constantes e muito mais rápidas ${ }^{\mathrm{I}}$. As leis, porém, por forças maiores, continuam a se mostrar anacrônicas à sua contemporaneidade.

12 THE BERKMAN GENTER FOR INTERNET \& SOCIETY at Harvard University. Repensando a música: um artigo embasador. In: Revista do Auditório do Ibirapuera Repensando a Música, 20II, p. II e 32.

13 The Library of Congress National Recording Preservation Plan. Sponsored by the National Recording Preservation Board of the Library of Congress, 2012, p. 70.

I4 Idem. Repensando a música: um artigo embasador, 20II, op. cit., p. 46. 


\section{Pharmakon: a memória relegada à ambiguidade da ferramenta}

O processo da memória histórica tem em seu início aquela apreendida em estado declarativo que se exterioriza no registro. É esse o fim do processo da memória que encontra, em seu interior, a prova documental como elemento que a constitui (RICCEUR, 2007, p. I54 e I55). Este último ponto, porém, não deve ser tratado como um fim em si mesmo. A prova documental, portanto, ainda deve estar submetida aos processos de armazenamento que passam a garantir não apenas as reminiscências, como também a vida útil dos documentos. Muito além da própria digitalização e das preocupações que cercam as fontes físicas e digitais, é necessário, porém, toda uma reflexão acerca das ferramentas para o acesso a estas fontes.

Mudando profundamente a forma de registrar e documentar a cultura e expressões artísticas, a era digital introduziu novos formatos de áudio. Acompanhando essas mudanças, arquivos institucionais têm digitalizado seus acervos em busca da preservação destes ${ }^{15}$. Engenheiros e especialistas acreditam que o futuro da preservação do áudio esteja no meio digital. Além da capacidade de copiar o documento analógico para o formato digital, com grande proximidade ao original, a digitalização permite grande facilidade no transporte, armazenamento e transmissão desses documentos, possibilitando um acesso público mais fácil, ágil e barato. E, ainda, mesmo os documentos digitais estando passíveis de deterioração, assim como os analógicos, alguns especialistas têm desenvolvido sistemas para administrar esses áudios, arquivando-os em repositórios periodicamente atualizados ${ }^{16}$. A questão, porém, se mostra mais complexa a partir do momento em que a digitalização da sociedade, seu meio e suas ações passam a modificar suas relações de constituição e preservação da memória.

A primeira dessas mudanças está na noção de inscrição, por exemplo, de um espaço corporal imediatamente vinculado ao espaço do ambiente. Tendo a historiografia como inerente à memória arquivada, ao mesmo tempo em que todas as operações cognitivas ulteriores estão passíveis de serem recolhidas pela epistemologia do fazer histórico, são as espacialidades corporal e ambiental

I5 THE NATIONAL RECORDING PRESERVATION BOARD. Capturing analog sound for digital preservation. In: ROUNDTABLE DISGUSSION OF BEST PRACTICES FOR TRANSFERRING ANALOG DISCS AND TAPES. Report, March 2006, p. IV.

I6 THE NATIONAL RECORDING PRESERVATION BOARD. Capturing analog sound for digital preservation. In: ROUNDTABLE DISGUSSION OF BEST PRACTIGES FOR TRANSFERRING ANALOG DISGS AND TAPES. Report, March 2006, p. 2. 
grandes evocadoras das lembranças. Como seriam, porém, as alternâncias de repouso e de movimento que constituem o ato de habitar, dentro do meio digital? $\mathrm{O}$ ato de habitar está indissociável do ato de construir, tendo em seu interior os espaços vividos e os espaços geométricos. Portanto, é no habitar e no construir que reside a aproximação geográfica e temporal da inscrição corpórea associada à memória (RICEUUR, 2007, p. I56 a I58). Como, porém, se dá o ato de habitar dentro do meio digital? A sensação de uma espacialidade construída de informações tem a vertigem como sensação imediata em relação às ondas de conteúdos que aparecem e logo somem - e retornam uma ou mais vezes em alguns casos - à vista. O sentimento ordenador e indicador ficou relegado ao histórico do navegador e, apenas, a ele. Voltar a uma página seis meses após sua última visita pode ser uma experiência concreta de perder a sensação de espacialidade que suas percepções cognitivas estão passíveis de apreender. $\mathrm{O}$ vazio deixado por diversos ambientes construídos por incontáveis agentes da internet constituem a fragilidade da arquitetura digital, assim como o esquecimento de diversas memórias inseridas neste meio.

A segunda está no próprio fim documental. A preocupação acerca das técnicas e ferramentas de memorização pode ser encontrada já em Platão. O nascimento mítico da escrita, representado em Fedro, tem em seu tema o destino da memória. A noção associada ao pharmakon, que o deus oferece ao rei, no mito, nos apresenta uma ambiguidade insuperável na problemática da memória, mas que também coloca em confronto grande parte das publicações atuais sobre o papel e a importância da internet, apresentados no cotidiano atual. Ou seja, em todas as imbricações do mito, a problemática se dá na ambiguidade da escrita enquanto um remédio ou um veneno para a memória - um pharmakon, suscitando a ambiguidade da própria palavra. Seria a escrita - não a memória, mas a reminiscência - uma memória sobressalente, exterior, a memorização e a rememorização. Em certo momento, porém, a recusa à escrita no mito dá lugar à complexidade dos discursos. Ambos os modos de discursos - escrito ou não - continuam aparentados como irmãos, principalmente em razão dos dois serem escrituras, inscrições, sendo que é na alma o local onde o "verdadeiro discurso" está inscrito. É com esse parentesco profundo proposto que se torna possível afirmar que "o discurso escrito" é, de certa forma, "uma imagem" daquilo que na memória viva é "vivo", "dotado de uma alma", rico de "seiva", sendo assim autorizado se falar em escrita "viva", no caso da escrita da alma, e em "jardins de caracteres escritos". É nessa oposição - sem abandonar o parentesco - que aquele que escreve (o "agricultor") - acumulando um tesouro de rememorações para si mesmo venha a se esquecer graças à "esquecidiça velhice" - se "deleitará" ao observar "brotar essas tenras culturas" (RICEUR, 2007, p. I53). 
Temos, portanto, uma segunda citação e natureza do esquecimento. Antes citado como induzido pelo dom da escrita, aparece agora como um malefício da idade. Não seria então, assim como proposto por Paul Ricœur ao analisar o mito, a luta contra o esquecimento aquilo que preserva o parentesco entre "o irmão abusivo e o irmão legítimo"? Encontra-se agora a dialética em que a oposição entre uma memória e outra se torna secundária. Os escritos não passam de uma memória muleta para os discursos "escritos na alma" (Idem, 2007).

Além das questões subjetivas e um tanto abstratas, o fato concreto é que a efemeridade dos documentos digitais, assim como discorrido por Juan André Bresciano, que reside na vida útil digital, ainda não chega perto dos documentos analógicos como o papel, ou então de um vinil ou Compact-Disc. Portanto, sendo a primeira memória musical aquela que se dá exatamente na memória pessoal de cada indivíduo, e sendo a memória digital um recurso para auxiliar e evitar o esquecimento, não depositamos confiança demais em uma memória muleta, uma bengala digital que talvez possa estar rachada ou então simplesmente passível de sumir subitamente? E se considerarmos, por outro lado, a capacidade de rápida e fácil multiplicação das copias digitais?

O terceiro ponto, fechando essas relações que interferem na memória digital, é exterior a este meio, mas age nele de maneira direta. Mais que a desorientação espacial e a vida útil ainda curta dos documentos digitais, é a ação de grandes empresas e gravadoras que se esforçam em domar e controlar o meio digital, fazendo-o operar contra uma lógica interna orgânica, que deve figurar como uma das questões mais sensíveis a esta problemática: não a digitalização e preservação dos documentos, mas, sim, sua distribuição e acessibilidade. Historicamente, momentos de saltos nas ferramentas técnicas ou tecnológicas foram acompanhadas pelos esforços das leis em não se tornarem obsoletas ou entraves para estas. Diferente do avião para a noção de propriedade privada norte-americana, ou do caminhão para a indústria de ferrovias (sobre estas, ver LESSIG, 2006), a internet tem como característica interna ao seu estado tecnológico o ato de abrigar em suas dinâmicas outras tecnologias, serviços e comportamentos. A cultura digital não elimina a anterior ou absorve-a até anulá-la, mas modifica-a até qualificar a cultura em seu conjunto (PÉREZ TAPIAS, 2006, p. I6). Um exemplo destas mudanças está em como a lei regulamentou, até então, a cultura comercial e não-comercial. A internet modificou tradições tão antigas quanto a própria República, e, durante quase toda essa tradição, a cultura não-comercial foi essencialmente não-regulada, ou seja, não havia interesse e nem preocupação direta em relação a criação ou difusão da cultura não-comercial. A forma cotidiana de compartilhamento e transformação de cultura através de contar histórias, representando cenas teatrais 
ou da televisão, compartilhando música e gravando fitas, era ignorada pela lei, diferente da criatividade comercial (LESSIG, 2006, p. 29 a 3I).

Pressionada pelas grandes empresas de comunicação, porém, a internet passou a controlar o que até então estava livre em seu cotidiano. Pela primeira vez, a forma cotidiana de criar e compartilhar cultura está ao alcance das diretrizes legais. Passando a controlar uma grande quantidade de cultura e criatividade, a sociedade é "cada vez menos uma cultura livre e cada vez mais uma cultura de permissão" (Idem, 2006, p. 30). A possibilidade da construção e do cultivo da cultura, em seu interior, sendo um processo realizado por muitas pessoas, extrapolando os limites locais, é essa força das possibilidades de uma nova dinâmica cultural que ameaçou as indústrias de conteúdo estabelecidas. Ao invés, porém, de utilizar as ferramentas digitais para uma transformação na forma de produção, reprodução e distribuição dentro de uma nova forma de pensar e produzir cultura, essas grandes empresas e gravadoras estão usando a lei - através de seus poderes - para protegê-los contra esta nova tecnologia, recriando a internet antes que ela os recrie (Idem, p. 30). Em I996, quando o MP3 se popularizou, as gravadoras não tinham ninguém que dialogasse e entendesse a novidade, apenas advogados empenhados na defesa contra um inimigo, sedento por música, agora ao alcance, em listas organizadas, comentadas, com os mecanismos mais transparentes para medir o sucesso do novo meio e forma: o número de pessoas que disponibilizam o incontável número das músicas digitais. A estratégia foi, portanto, processar afirmando que era crime disponibilizar gratuitamente músicas protegidas por direitos autorais (SCHMIDT, 20II).

Assim como a história das ferramentas técnicas e tecnológicas, é o caráter ambíguo inerente a todas elas que aqui passa a figurar. Mais que uma ambiguidade, a internet se mostra ambígua como ferramenta incerta em seu futuro. A possibilidade de um grande acervo universal com amplo acesso pode, porém, esbarrar em formas obsoletas a seu novo tempo e contexto ${ }^{17}$. Mais que conter, os sólidos tendem a solidificar os líquidos da digitalização, ao mesmo tempo em que a confiança cega no próprio meio digital apresenta um risco à memória musical. É no desenvolvimento, portanto, de uma arquitetura melhor adaptada para a construção de uma memória - através de metadados, sistemas de hospedagem e a evolução do próprio meio digital - concomitante com os próximos passos das leis que regem a imensidão digital, que residem possibilidades de construção confiável de uma memória mneme ou anamnesis da música.

I7 Mais sobre questão de copyright e controle na internet ler: LESSIG, Lawrence. Cultura livre: como a grande mídia usa a tecnologia e a lei para bloquear a cultura e controlar a criatividade. São Paulo: Trama, 2006. 


\section{Referências bibliográficas}

BAUMAN, Zygmunt. Modernidade líquida. Rio de Janeiro: Jorge Zahar, 2008.

BRESCIANO, Juan Andrés. La historiografía en el amanecer de la cultura digital: Innovaciones metodológicas, discursivas e institucionales. Montevidéu: Ediciones Cruz del Sur, 20I0, p. IO.

CASTELLS. Manuel. A mídia de massas individual. 2010. Disponível em: <http:// www.diplomatique.org.br/edicoes_especiais_artigo.php?id=3>. Acesso em: I2/O3/2OI5.

CERTEAU, Michel. A invenção do cotidiano. Rio de Janeiro: Ed. Vozes, I994.

JOHNSON, Steven. Cultura da interface. Rio de Janeiro: Jorge Zahar, 200I, p. I9, 20 e 23.

LESSIG, Lawrence. Cultura livre: como a grande mídia usa a tecnologia e a lei para bloquear a cultura e controlar a criatividade. São Paulo: Trama, 2006.

MORAES, José Geraldo Vinci. História e música no Brasil. São Paulo: Alameda, 20 Io.

MORAIS, J. G. V. \& MACHADO, G. Música em conserva. Revista Auditório, nº I, 2 OII.

PÉREZ TAPIAS, José Antônio. Internautas e náufragos: a busca do sentido na cultura digital. São Paulo: Loyola, 2006.

RICEEUR, Paul. A memória, a história, o esquecimento. São Paulo: Editora da UNICAMP, 2007.

SCHMIDT, Pena. Reinventar a indústria da música. Revista Auditório, no I, 20 II.

THE BERKMAN GENTER FOR INTERNET \& SOCIETY at Harvard University. Repensando a música: um artigo embasador. Revista do Auditório do Ibirapuera Repensando a Música.

The Library of Congress National Recording Preservation Plan, sponsored by the National Recording Preservation Board of the Library of Congress, 2012.

THE NATIONAL REGORDING PRESERVATION BOARD. Capturing analog sound for digital preservation. In: ROUNDTABLE DISCUSSION OF BEST PRACTICES FOR TRANSFERRING ANALOG DISGS AND TAPES Report, March 2006.

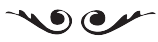

Gabriel de Oliveira Piotto - Graduando em História pela Universidade de São Paulo.

gabriel.piotto@usp.br 